\title{
Environmental Sustainability Behaviours of Employees of Bulk Oil Distribution Companies in Tema, Ghana
}

\author{
Seth Cudjoe $^{1}$, Samuel Kwabla Alorvor ${ }^{1}$, Elias Megbetor ${ }^{2}$ \\ ${ }^{1}$ Department of Geography, Environmental Management \& Energy Studies, University of Johannesburg, Johannesburg, South Africa \\ ${ }^{2}$ Department of Development and Environmental Studies, Wisconsin International University College, Accra, Ghana
}

Email address:

cudjoe@andrews.edu (S. Cudjoe), samuelalorvor@gmail.com (S. K. Alorvor), emegbetor@gmail.com (E. Megbetor)

\section{To cite this article:}

Seth Cudjoe, Samuel Kwabla Alorvor, Elias Megbetor. Environmental Sustainability Behaviours of Employees of Bulk Oil Distribution Companies in Tema, Ghana. International Journal of Economy, Energy and Environment. Vol. 6, No. 4, 2021, pp. 76-80.

doi: $10.11648 /$ j.ijeee.20210604.11

Received: March 15, 2021; Accepted: March 26, 2021; Published: July 29, 2021

\begin{abstract}
Many organisations have acknowledged the call for environmental sustainability behaviours but there is little information about these behaviours exhibited by employees at the work place. The study sought to find out the environmental sustainability behaviours exhibited by employees in bulk oil distribution companies in Tema, Ghana. The objective of the study was to find out the sustainability behaviours adopted by employees and factors that influenced the decision to adopt environmental sustainability behaviours. The questionnaire survey was adopted to collect data from 50 employees of Fueltrade Limited. The survey result indicated that employees engaged in behaviours such as reducing waste, recycling and reuse of materials, proper disposal of waste, energy conservation, and the reduction in the wastage of resources. Furthermore, the results indicated that adopting environmental sustainability behaviours was to some extent fret with challenges such as lack of managerial support for the adoption of employee environmental sustainability behaviours; environmental sustainability not being a high business priority; practicing environmental sustainability behaviours takes too much time and to an extent a lack of management support for sustainability behaviours at the workplace. The study recommends among others that organisations should create environmental awareness by training and providing information to employees. Also, organisations should put in place reward systems to incentivize employees who engage in sustainability behaviours at the work place so as to motivate other employees to engage in sustainability behaviours.
\end{abstract}

Keywords: Greenhouse Gases (GHGs), Environmental Sustainability Behaviours (ESB), Employees, Bulk Oil Distribution Companies (BDCs)

\section{Introduction}

There is international consensus for the need to reduce greenhouse gas emissions to minimize the impact of climate change [7]. The intention to act has become increasingly vocal with world leaders agreeing at the UN Climate Change Conference in Paris in 2015 to phase out fossil fuel use by the end of the century [2]. Fossil fuel use account for $84 \%$ of world energy consumption and contribute significantly to greenhouse gas emissions [10]. The widely used fossil fuel that contribute significantly to greenhouse gas emissions is oil and gas. The oil and gas industry contributes positively to the economies of countries in a number of ways including: generating direct and indirect jobs; contributing substantial tax and other types of revenue to governments; investing in the long-term social and economic success of the communities in which they operate. In spite of these contributions, the operations of the oil and gas industry have adverse impacts on communities and the environment $[1,14]$.

In the wake of this global challenge, a number of organizations are attempting to implement environmental sustainability initiatives [2, 9, 11]. Organisations in Ghana are making attempts to implement sustainability initiatives. For instance, Fan Milk Company Limited has subscribed to the concept of environmental sustainability. The managers of the company have developed plans to use material and processes that conserve resources and prevent pollution of the natural environment. The implementation of sustainability initiatives has resonated with Bulk Oil 
Distribution Companies (BDCs), a sector of the oil and gas industry in Ghana that distributes fuel to Oil Marketing Companies (OMCs) across the country. The activities of BDCs are seen to impact negatively on the environment. Managers of BDCs are therefore developing and implementing environmental sustainability initiatives as a commitment to reducing their environmental footprint.

Statement of Problem

The Bulk Oil Distribution Companies (BDCs) in Ghana have over the years been criticized over how their operations impact negatively on the environment. The high environmental impacts are mainly attributed to the lack of effective sustainability management and processes to decrease the negative effects of their operations on the environment. In the wake of this negative impacts a number of BDCs have started implementing environmental sustainability initiatives in an effort to reduce their environmental footprint. The commitment to do this is buttressed by the Environmental Management Plans of the BDCs. Some BDCs are also developing organizational strategies that focuses on employees and their sustainable behaviours as sustainability is seen as a shared responsibility. Unfortunately little is known about the sustainability behaviours of employees and the factors that influence these sustainable behaviours. This study was therefore set out to find out the environmental sustainability behaviours adopted by employees of Fueltrade, a Bulk Oil Distribution Company located in Tema; the factors that influence employees to adopt environmental sustainability behaviours; and the challenges that confront the adoption of environmental sustainability behaviours of employees.

\section{Methodology}

The purposive sampling technique was used to select Fueltrade Limited for the study as the company is the bulk oil distribution company with the largest market share (19\%) in the petroleum distribution business in Ghana. The purposive sampling technique was also used to select 50 employees of Fueltrade Limited for the purposes of questionnaire survey. The selected employees were based at the company's Operations Hub at Tema. The decision to select only employees at the company's Operation Hub at Tema was influenced by the fact that every operational decision by the company is taken at the Tema Operations Hub.

The employees selected for the study included two (2) executive officers, six (6) line managers, and forty-two (42) employees who held no managerial position. The purposive sampling technique helped in selecting respondents who had knowledge on environmental sustainability behaviours. Since environmental sustainability behaviours are a workplace culture, the researcher believes the purposive sampling technique was the best suited method to use for the selection of participants for the study.

\section{Results and Discussion}

This section presents and analyses data from the field work that sought to find out the environmental sustainability behaviours of employees of Fueltrade Limited.

\subsection{Employee Environmental Sustainability Behaviours}

The first objective of the study was to find out the environmental sustainability behaviours adopted by employees of Fueltrade Ltd. Multiple responses were allowed by the researcher. The survey results as illustrated in Table 1 indicate that all respondents saved the company's resources by printing less and driving company's cars less frequently as a form of sustainability behaviour. A total of $32 \%$ of the respondents opined that they always practised this environmental sustainability behaviour. Also $42 \%$ of the respondents stated they practised this sustainability behaviour most of the time whilst $28 \%$ of the respondents practised this sustainability behaviour sometimes. The survey result indicating that all fifty (50) respondents adopted resource saving behaviours does not come as a surprise as there have been massive campaigns by the Ghana Ministry of Environment, Science and Technology encouraging people to adopt sustainability behaviours at home and workplace.

The results also revealed that out of the 50 respondents who participated in the questionnaire survey, $62 \%$ stated they found alternatives to private car use most of the time by joining public transport to and from work as an environmental sustainability behaviour. Also $8 \%$ of the respondents indicated they practised this sustainability behaviour always whilst $12 \%$ of the respondents stated they practised this environmental sustainability behaviour most of the time. A total of $18 \%$ of the respondents stated that they do not find alternatives to car use by joining public transport to work, and thus does not practice this sustainability behaviour. There has been a lot of advocacy on the use of public transport in recent years because dependence on private car use has been recognised as the largest contributor to atmospheric pollutant emissions from the transport sector.

Table 1. Employee Environmental Sustainability Behaviours.

\begin{tabular}{|c|c|c|c|c|c|}
\hline Employee Environmental Sustainability Behaviours at FLT & Sometimes & Most of the time & Always & Never & Total (\%) \\
\hline Resource Savings (printing less, driving company cars less frequently) & 28 & 42 & 30 & 0 & 100 \\
\hline Finding alternatives to private car use & 62 & 12 & 8 & 18 & 100 \\
\hline Recycle paper, glass, or cans & 10 & 56 & 24 & 10 & 100 \\
\hline Energy saving (switching off lights, computers etc) & - & - & 100 & 0 & 100 \\
\hline Economic use of resources without wastage & - & - & 100 & 0 & 100 \\
\hline
\end{tabular}


Furthermore, on the question of recycling paper, glass, and cans as an environmental sustainability behaviour, $56 \%$ of the respondents opined that they practised this sustainability behaviour most of the time whilst $24 \%$ of the respondents stated they practised this sustainability behaviour always. Also $10 \%$ of the respondents stated they did not practice this as a sustainability behaviour. Recycling is simply the process of using materials that have already been used. One of the main benefits of recycling is reusing materials so that you do not need to harvest more natural resources from the environment, or at least slowing down the rate at which natural resources need to be used. The high number of respondents practicing recycling in the study organisation is an indication that the global campaign for recycling is resonating with the people.

The results as illustrated in Table 1 revealed that all the fifty (50) respondents who opined they disposed of waste properly practised this sustainability behaviour always. The respondents stated that there were two bins in every department of the organisation for waste separation. The materials reused included disposal cups, plastics bottles and polythene bags, and A4 sheets. Printer toners were refilled after use rather than buying new toners. The respondents pointed out that the recycling and reuse of materials and waste separation has helped in a better management of waste generated by the organisation. A respondent opined that by recycling, reusing and reducing waste, the amount of waste sent to the landfills is reduced to the barest minimum.

Additionally, all fifty (50) respondents who practised energy saving as a sustainability behaviour practised this behaviour always. The respondents revealed they switched off lights and opened window curtains as a way of saving energy. The respondents also indicated that they put off computers, printers and power stabilizers when the equipment are not in use. The respondents also remarked that it was obligatory for staff of the company to turn off refrigerators and air conditioners after close of work.

The study revealed that all fifty (50) respondents always used company materials economically without wastage as an environmental sustainability behaviour. The respondents opined that printing documents is discouraged as soft copies were preferable since it reduces paper and toner usage. Also using the organisation's Wi-Fi connection for downloading files which were irrelevant to employee's job functions was discouraged so as to minimize internet data consumption.

\subsection{Factors That Influence Employee Environmental Sustainability Behaviours}

The second objective of the study was to establish the factors that influenced the adoption of environmental sustainability behaviours. In order to get the full facts, respondents were asked to provide multiple responses to the research question. The results as illustrated in Table 2 established that $58 \%$ of the respondents adopted sustainability behaviours because of the financial savings it brought to the company. Also $76 \%$ of the respondents pointed out that they practised sustainability behaviours as it is a requirement for the renewal of ISO 26000 and ISO 9001:2008 certifications. The respondents opined that compliance to these certifications was important since it helps the company access capital from international financial agencies.

Table 2. Factors that influence environmental sustainability behaviours of employees.

\begin{tabular}{lll}
\hline Factors & Number of responses & \% \\
\hline To make financial savings for the company & 29 & 58 \\
To help achieve relevant accreditation (e.g. ISO 9001:2008) & 38 & 76 \\
Help meet statutory obligations and responsibilities for sustainability & 18 & 36 \\
To reduce company's environmental footprint & 44 & 66 \\
To enhance reputation and image of organisation & 21 & 42 \\
Actions of managers and supervisors & 16 & 32 \\
Personal values, beliefs and norms & 32 & 64 \\
Organisational values & 21 & 42 \\
\hline
\end{tabular}

*Multiple responses from respondents

The result also revealed that $36 \%$ of the respondents opined they adopted sustainability behaviours to help meet the company's statutory obligations to the Environmental Protection Agency. Also 66\% of the respondents stated that adopting sustainability behaviours was to help reduce the environmental footprint of the company whilst $42 \%$ of the respondents stated that adopting environmental sustainability behaviours helped to enhance the image of the company since in recent times there have been a lot of advocacy in Ghana encouraging firms to adopt sustainability behaviours to reduce their impact on the environment. A total of $32 \%$ of the respondents stated that their line managers influenced their decision to adopt some sustainability behaviours in their department. Also $64 \%$ of the respondents indicated that adopting sustainability behaviours at the work place was influenced by the personal values, belief and norms they hold about the environment whilst $42 \%$ of the respondents stated that they were influenced by organizational values to adopt sustainability behaviours at the work place. The result confirms previous studies that individual values held about the environmental may influence the way the individual related to the environmental $[4,13]$. The authors point out that the individual values held about the environment may influence the sustainability behaviours of the individual in the quest to protect the environment. 


\subsection{Challenges That Confront the Adoption of Environmental Sustainability Behaviours by Employees}

The third objective of the study was to find out the factors that hindered the adoption of environmental sustainability behaviours at the work place. The researcher sought to find out whether employees showed interest in sustainability behaviours at the work place. The question of colleagues showing little interest about the environment was posed to respondents. The result as illustrated in table 3 revealed that $58 \%$ of the respondents disagreed their colleagues showed little interest about the environment whilst $18 \%$ of the respondents strongly disagreed with the statement. The result suggest that employees of Fueltrade Limited showed concern for the environment and by that adopting sustainability behaviours at the workplace.

Table 3. Challenges that confront the adoption of environmental sustainability behaviours by employees.

\begin{tabular}{|c|c|c|c|c|c|c|}
\hline \multirow[b]{2}{*}{ Challenges } & \multicolumn{6}{|c|}{ Responses } \\
\hline & $\begin{array}{l}\text { Strongly } \\
\text { disagree }\end{array}$ & Disagree & Neutral & Agree & $\begin{array}{l}\text { Strongly } \\
\text { Agree }\end{array}$ & Total (\%) \\
\hline Colleagues show little concern about the environment & 18 & 58 & 6 & 10 & 8 & 100 \\
\hline Costs of implementing ESB commercially not worthwhile & 58 & 26 & 4 & 8 & 4 & 100 \\
\hline ESB not a high business priority & 64 & 8 & - & 12 & 16 & 100 \\
\hline Lack of support from management & 66 & 34 & - & - & - & 100 \\
\hline
\end{tabular}

The result also revealed that the organisation organized annual training for staff on environmental sustainability and this has led to employees possessing some level of environmental knowledge. This explains why a large number of employees in the study organisation adopted environmental sustainability behaviours. A number of studies have revealed that environmental knowledge could impact sustainability behaviors. Individuals' knowledge of environmental problems and possible alternatives and solutions has on some occasions impacted the behaviors of people [6]. Other studies have also established the same conclusion that responsible environmental behaviors were effective only when individuals have the appropriate level of information on the environment [12].

The survey result as illustrated in Table 3 indicate that $58 \%$ of the respondents strongly disagreed the cost of implementing environmental sustainability behaviours is not commercially worthwhile. Whilst $26 \%$ of the respondents remained neutral on the subject matter, $4 \%$ of the respondents strongly agreed the cost of implementing ESB was not commercially worthwhile. The reason for a large number of respondents disagreements was based on the fact that adopting sustainability behaviours helped the company in meeting requirements for ISO certifications and also meeting EPA regulation requirements. It is important to note that regulations and standards determines market entry for organisations, and compliance to regulations and standards plays a central role in global trade competitveness. Compliance to regualtions creates a good business image for a company and for this reason companies invest in the necessary infrastructure and staff training to ensure these set standards are met.

The study also sought to find out whether practising sustainability behaviours was a business priority for the study company. The result as illustrated in Table 3 revealed that $64 \%$ of the respondents strongly disagreed environmental sustainability behaviours was not a high business priority of the study organisation. Also $16 \%$ and $12 \%$ of the respondents strongly agreed and agreed respectively that environmental sustainability behaviours was not a business priority of the study organisation. The results indicate that Fueltrade
Limited made practising sustainability beaviours in its facilties by employees a business priority.

The survey result also revealed that $66 \%$ of the respondents, strongly disagreed that there was lack of management support for the adoption of environmental sustainability behaviours whilst $34 \%$ of the respondents strongly disagreed there was lack of support from management for the adoption of employee environmental sustainability behaviours. The respondents opined management showed more interest in these environmental sustainability behaviours it was a requirement for the renewal of ISO and EPA permits. The respondents who strongly disagreed there was lack of management support opined that management have provided leadership to promote employee sustainability behaviours at the work place. Management also encouraged recycling and reuse of materials, and also held annual training events on environmental awarenenss for staff. The arguments put up by the respondents goes to confirm the position held by researchers that management support is vital if employee sustainability at the work place is to be achieved. Previous studies suggests that the attitude and direct personal involvement of top management and line managers and their ability to articulate why environmental sustainability is helpful to the organisation is also vital in achieving workplace sustainability [3]. It is important to note that when senior management have a strong belief in and commitment to environmental sustainability, they set an example for the rest of the employees. In summary, employees are more likely to take responsibility for environmental sustainability practices if they get sufficient support from above, and 'green leadership' in organisations is helpful to support environmental sustainability as the leaders inspire cultural changes and are recognized by the employees $[8]$.

\section{Conclusion}

The study found that employee sustainability behaviours was influenced by organizational values, personal values, beliefs and norms, actions of managers and supervisors, and 
the need to enhance reputation and the image of the organisation. The need to reduce the company's environmental footprint, meet statutory obligations and responsibilities, achieve relevant ISO and EPA certifications, and the need to make financial savings for the company also influenced the environmental sustainability behaviours of employees. The survey results indicated that adopting environmental sustainability behaviours is an initiative supported by management of Fueltrade Limited as the company has made sustainability issues a high business priority because of the enormous benefits available to the company for adopting this initiative.

\section{References}

[1] Bautista H. and Rahman K. M. M. (2016). Review On the Sundarbans Delta Oil Spill: Effects On Wildlife and Habitats. International Research Journal, 1 (43), Part 2, pp: 93-96. doi: 10.18454/IRJ.2016.43.143.

[2] Blok, V., Wesselink, R., Studynka, O., \& Kemp, R. (2015). Encouraging sustainability in the workplace: A survey on the pro-environmental behaviour of university employees. Journal of Cleaner Production, 106, 55-67. https://doi.org/10.1016/j.jclepro.2014.07.063.

[3] Cairns S, Newson C, Davis A. (2010). Understanding successful workplace travel initiatives in the UK. Transportation Research Part A: Policy and Practice 44 (7): 473-494. DOI: 10.1016/j.tra.2010.03.010.

[4] De Groot, J., \& Steg, L. (2008). Value orientations to explain beliefs related to environmental significant behaviors: How to measure egoistic, altruistic, and biospheric value orientations. Environment and Behaviors, 40 (3), 330-354.

[5] Gifford, R. (2014). "Environmental Psychology Matters," Annual Review of Psychology, 65 (1), 541-79.
[6] Gifford, R. \& Nilsson, A. (2014). "Personal and Social Factors that Influence Pro-environmental Concern and Behaviour: A Review," International Journal of Psychology, 49 (3), 141-57.

[7] IPCC, (2014). Summary for policymakers. In: Climate Change 2014: Mitigation of Climate Change. Contribution of Working Group III to the Fifth Assessment Report of the Intergovernmental Panel on Climate Change, pp. 1-31.

[8] Jones, C. \& Volpe, E. H. (2010). Organizational identification: Extending our understanding of social identities through social networks. Journal of Organizational Behavior J. Organiz. Behav. DOI: 10.1002/job.694.

[9] Lo, S. H., Peters, G. J. Y., \& Kok, G. (2012b). A review of determinants of and interventions for proenvironmental behaviors in organizations. Journal of Applied Social Psychology, 42 (12), 2933-2967.

[10] Lokhorst, A. M., Staats, H., \& Van Iterson, J. (2015). Energy saving in office buildings: Are feedback and commitmentmaking useful instruments to trigger change? Human Ecology, 43 (5), 759-768. https://doi.org/10.1007/s10745-015-9783-8.

[11] Ones, D., \& Dilchert, S. (2012). Employee green behaviors. In S. E. Jackson, D. S. Ones, \& S. Dilchert (Eds.): Managing HR for Environmental Sustainability. Jossey-Bass/Wiley.

[12] Schahn, J., \& Holzer, E. (1990). Studies of individual environmental concern: The role of knowledge, gender, and background variable. Environment and Behaviour, 22 (6), 767-786.

[13] Schultz, P. W., \& Zelezny, L. C. (1998). Values and proenvironmental behaviors: A five country survey. Journal of Cross-Cultural Psychology, 29, 540-558.

[14] Stohl, A.; Klimont, Z.; Eckhardt, S.; Kupiainen, K.; Chevchenko, V. P.; Kopeikin, V. M.; Novigatsky, A. N. (2013), "Black carbon in the Arctic: the underestimated role of gas flaring and residential combustion emissions", Atmos. Chem. Phys., 13 (17): 88338855, Bibcode: 2013ACP....13.8833S, doi: 10.5194/acp-13-8833-2013. 